\title{
Redistribution of Canine Splanchnic Blood Flow following Normotensive Hemorrhage ${ }^{1}$
}

\author{
Gordon L. Kauffman, JR., M.D., and Louis G. D'Alecy, Ph.D. \\ Department of Surgery, Section of General Surgery, and the Department of Physiology. University of \\ Michigan Medical Center, Ann Arbor, Michigan 48109 \\ Submitted for publication November 29, 1976
}

Stress ulceration of the gastric mucosa is a potential life-threatening complication of shock, sepsis, and severe trauma. Mucosal ischemia has been postulated as a factor contributing to the development of this lesion [8]. If mucosal ischemia does predispose to stress ulccration, then the redistribution of gastric mucosal blood flow in stressed animals should correlate with the pattern of simultaneous fundic involvement with antral sparing, observed clinically $[5,6]$.

Thesc experiments werc designed to study changes in splanchnic blood flow in unanesthetized dogs subjected to the stress of normotensive hemorrhage. The radioactive microsphere technique was used to evaluate changes in regional blood flow in twelve areas of gastric body mucosa, three areas of gastric antral mucosa, the postbulbar duodenum, and the pancreas. Blood flow was determined for each area (milliliters per minute per $100 \mathrm{~g}$ ) to identify patterns in regional flow reduction which might correlate with clinical observations in stress ulceration and thereby suggest a mechanism for protection of the gastric antral mucosa from stress-induced ischemic damage.

\section{METHODS}

Gastric mucosal, duodenal, and pancreatic blood flow was measured in 10 unanesthetized dogs, 15-25 kg, using the radioactive microsphere technique. It has been shown that this method correlates well

\footnotetext{
${ }^{1}$ Supported by N.I.H. Grants No. AM08716 and 013824.
}

with gastric blood flow as determined by aminopyrine clearance and venous outflow methods [1].

Chronic indwelling catheters were surgically placed into the left atrium and left femoral artery of each animal 3 to 4 days prior to the experiment. This allowed recovery from anesthesia prior to the experiments. Catheters were buried subcutaneously and brought out into the interscapular area to prevent tampering with them during the recovery period. All animals were fasted for $18 \mathrm{hr}$ prior to the experiment, while water was allowed ad libitum.

Each animal was placed in a Pavlov stand. The femoral artery catheter was connected to a pressure transducer for measurement of pulsatile pressure, mean arterial pressure, and heart rate on an oscillograph (Gould Brush 200). A suspension of 6-9 $\times 10^{5}{ }^{141} \mathrm{Ce}-$ labeled $15-\mu \mathrm{m}$ microspheres in $5 \mathrm{ml}$ of $39^{\circ} \mathrm{C}$ normal saline was infused via the atrial catheter. A simultaneous arterial reference sample was withdrawn via the femoral artery catheter at $6.60 \mathrm{ml} / \mathrm{min}$. Following the infusion of microspheres the heart rate and mean arterial pressure were monitored to verify that these parameters remained at preinfusion levels.

Animals in the control group $(N=5)$ remained in the stand for $\mathbf{3 0}$ min during which time no procedure was performed. At the conclusion of $30 \mathrm{~min},{ }^{85} \mathrm{Sr}$-labeled microspheres were infused using the same protocol.

Animals in the experimental hemorrhage group $(N=5)$ were weighed, and approxi- 
mate blood volumes were calculated. After the infusion of the ${ }^{141} \mathrm{Ce}$-labeled microspheres, $20 \%$ of calculated blood volume was withdrawn over a 30-min period, via the femoral artery catheter. All animals exhibited gingival pallor and developed a tachycardia [mean heart rate (HR) increased from 98 to 160 beats/min]. Mean arterial pressure (MAP) changed slightly from 113 to $108 \mathrm{~mm} \mathrm{Hg}$. Any animal whose MAP fell more than $10 \mathrm{~mm} \mathrm{Hg}$ following hemorrhage was excluded from the study. When MAP and HR were stable, the ${ }^{85} \mathrm{Sr}$-labeled microsphcres wcre infused via the atrial catheter. All animals were sacrificed with Uthol (W. A. Butler Co., Col, Ohio 43228) solution.

The stomach, duodenum, and pancreas were removed. The stomach was opened along the greater curve and divided into 15 segments ( 12 body and 3 antrum) and each segment was dissected into mucosa and corresponding muscular layers. A single segment of full-thickness duodenum and pancreas was also studied. The specimens were weighed. Specific tissue and arterial reference radioactivity for both isotopes was counted in a Searle 1195 dual channel automatic gamma counter. Blood flow (mil- liliters per minute per $100 \mathrm{~g}$ ) was calculated using the arterial reference method [10].

Gastric body mucosal blood flow was calculated for each segment as well as the mean of the twelve segments. Gastric antral mucosal blood flow was calculated as the mean of the three antral segments. Mean blood flow as determined by the ${ }^{141} \mathrm{Ce}$ labeled microspheres was compared to that obtained from the ${ }^{85} \mathrm{Sr}$-labeled microspheres for all four tissues. Paired $t$ analysis was used to evaluate significant blood flow changes for the five animals in each group. After hemorrhage, the percentage change in blood flow was calculated for each of the 15 gastric mucosal segments. Using Student's $t$ analysis, the percentage change in the cardia (four samples) was compared to the changes in the preantral region (four samples).

\section{RESULTS}

Mean blood flow in control (no hemorrhage) animals was not significantly different when comparing the ${ }^{141} \mathrm{Ce}$ values with the ${ }^{85} \mathrm{Sr}$ values for any of the tissues studied (Table 1). These data reaffirm the validity of microsphere blood flow measurements as well as confirm a relatively uniform splanch-

\section{TABLE 1}

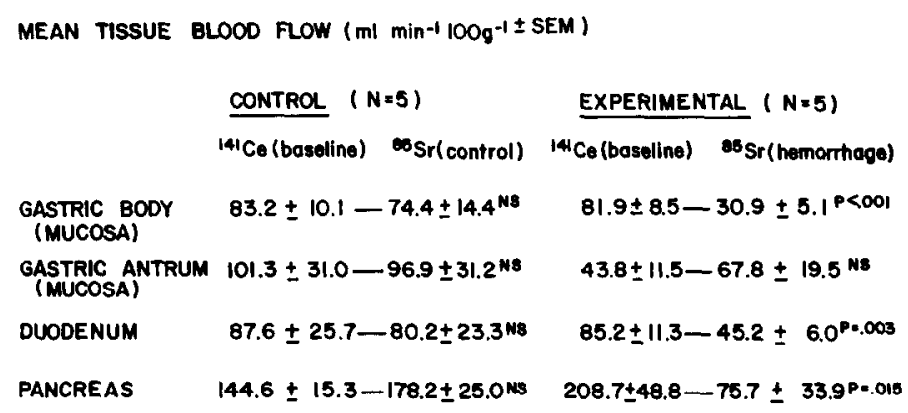

STATISTICAL ANALYSIS : PAIRED T TEST

\footnotetext{
Mean tissue blood flows shown under the Control column compare the values for five animals in the normovolemic state $\left({ }^{141} \mathrm{Ce}\right)$ to those after a 30 -min waiting period $\left({ }^{85} \mathrm{Sr}\right)$ during which no procedure was performed. No significant difference was found between these values for any of the four tissues studied. Mean tissue blood flows shown under the Experimental column compare the normovolemic state $\left({ }^{(41} \mathrm{Ce}\right)$ to that following normotensive hemorrhage $\left({ }^{85} \mathrm{Sr}\right)$. Significant blood flow reduction was found in the gastric body mucosa, duodenum and pancreas but not in the gastric antral mucosa.
} 
nic blood flow during the time period necessary for our experiments in an unanesthetized dog. Pancreatic blood flow was twice the gastric mucosal and duodenal flow in the resting state.

Following normotensive hemorrhage, significant blood flow reduction was found in the gastric body mucosa, duodenum, and pancreas. Gastric body mucosal flow fell from 81.9 to $30.9 \mathrm{ml} \mathrm{min}^{-1}(100 \mathrm{~g})^{-1}(-62 \%)$. Flow in the duodenal segment fell from 85.2 to $45.2 \mathrm{ml} \mathrm{min}^{-1}(100 \mathrm{~g})^{-1}(-47 \%)$. Pancreatic blood flow fell from 208.7 to 75.7 $\mathrm{ml} \min ^{-1}(100 \mathrm{~g})^{-1}(-64 \%)$. All of these changes were statistically significant when subjected to the paired $t$ analysis.

The gastric antral mucosa behaved in a different way. Mean blood flow changed from 43.8 to $67.8 \mathrm{ml} \mathrm{min}^{-1}(100 \mathrm{~g})^{-1}$, but this change was not statistically significant.

Seromuscular blood flow in the gastric body and antrum was found to be one order of magnitude lower than the corresponding mucosa. Following hemorrhage, antral seromuscular blood flow changed from 11.4 to $7.9 \mathrm{ml} \mathrm{min}^{-1}(100 \mathrm{~g})^{-1}$ and that of the gastric body changed from 4.9 to 5.4 $\mathrm{ml} \min ^{-1}(100 \mathrm{~g})^{-1}$. Neither change was statistically significant.
As shown in Fig. 1, blood flow was determined for the twelve segments of gastric body mucosa and three segments of the gastric antral mucosa in control and hemorrhage conditions. Percentage change was calculated from these data. Comparison of the percentage change in the four segments of cardia with the four preantral values shows a significantly greater blood flow reduction in the cardia $(-65 \%)$ than in the preantral regions $(-59.5 \%)$ ( $P=0.047$ by Student's $t$ analysis).

\section{DISCUSSION}

In order to prevent and treat stress ulceration of the gastric mucosa more effectively, significant predisposing conditions must be elucidated. The role of mucosal blood flow as a contributing factor is not well understood. The results of these experiments show that the gastric body mucosa, duodenum, and pancreas respond to stress with a significant reduction in blood flow while the blood flow in the gastric antral mucosa is not significantly changed. These results correlate with clinical observations of simultaneous fundic involvement with antral sparing in stress ulceration.

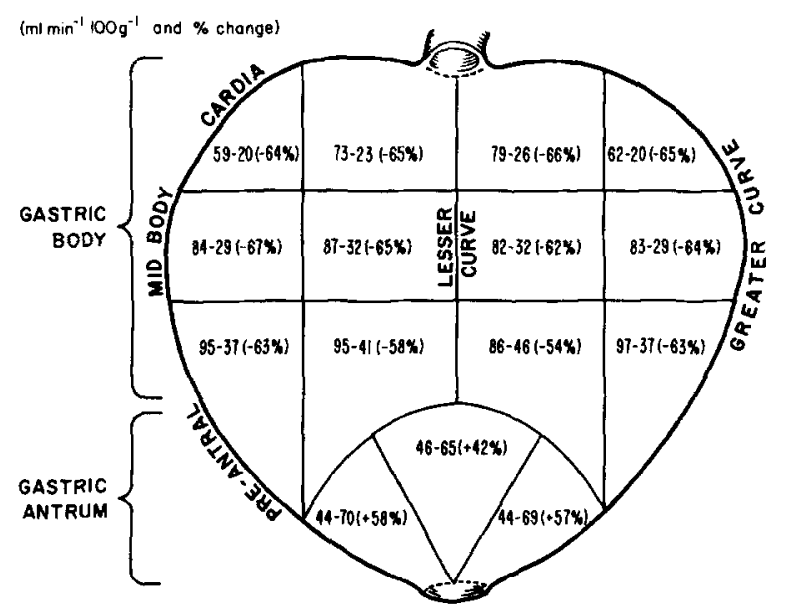

FIG. 1. Response of regional gastric blood flow to normotensive hemorrhage. Representation of canine stomach open along the greater curvature. The hody has been divided into twelve regions, the antrum three. Numbers in each region represent resting normovolemic blood flow and flow after hemorrhage (percentage change in parentheses). Comparison of percentage change in the cardia with changes in preantral regions show significantly greater blood flow reductions in the cardia than in preantral regions ( $P<0.05$ by Student's $t$ analysis). The cardia appears to have the greater potential for ischemia than does the remaining stomach. Marked reductions in blood flow were not observed in the antrum. 
Using the radiorubidium technique in anesthetized dogs, Broadie and others [2] have shown a $29 \%$ reduction in duodenal blood flow without change in blood flow to the antrum and body following posterior hypothalamic stimulation. They also have shown an $88 \%$ increase in antral blood flow in response to hypoxia without change in duodenal or gastric body mucosal flow. Labeled microspheres were used to study the effect of endotoxic shock on the distribution of gastric blood flow in piglets by Richardson and others [7], who showed that maximum flow reduction $(-62.2 \%)$ was found in the body of the stomach where ulcers occurred. Shirazi and coworkers [9] have recently shown, with the use of microspheres, that hemorrhagic shock caused a significant reduction of blood flow within gastric tissue and that the fundic mucosal flow decreased more than the antral mucosa. All of these studies, as well as ours, suggest that gastric antral blood flow is less subject to change than the blood flow in the gastric body in stressed animals.

Sympathetic outflow under stress is often masked by anesthesia. Vatner and Braunwald [11] have demonstrated changes in an organism's integrative response to stress with anesthesia and have emphasized the importance of conducting experiments using unanesthetized animals where integrative control of circulation is important. Unanesthetized animals were used in these experiments and well served the purpose of studying small changes in sympathetic tone. All hemorrhaged animals developed a tachycardia and exhibited gingival pallor. Splenectomy was not performed since any interference with blood supply to the stomach would involve sympathetic nerves and possibly affect regional blood flow to that area. A major concern was the investigator's inability to control autonomic functions in an unanesthetized animal. As much as possible, external sensory stimulation was kept to a minimum. More consistent results might be obtained in animals trained in a Pavlov stand.
Mean control gastric blood flow in these studies is similar to values reported by others [4, 9] using the radioactive microsphere technique $\left(50-100 \mathrm{ml} \mathrm{m^{-1 }}\right.$ (100 $\mathrm{g}^{-1}$ ). Resting mucosal flows were consistent in the same horizontal gastric plane but increased from the cardia to the antrum. Reproducibility of flow values by two different microsphere infusions, as shown in Table 1, Control, verified the technique. Flow as determined by the ${ }^{141} \mathrm{Ce}$ infusion between the two groups of animals also shows consistent results for all tissues, except the antrum where flow appears to be less in the Experimental $\left(43.8 \pm 11.5 \mathrm{ml} \mathrm{m^{-1 }}(100\right.$ g) $\left.{ }^{-1}\right)$ than in the Control group (101.3 \pm 31.0 $\left.\mathrm{ml} \min ^{-1}(100 \mathrm{~g})^{-1}\right)$. Statistical analysis revealed no significant difference between these flow values ( $P>0.10$ by Student's $t$ analysis). The apparent difference can be attributed to a single unusually high flow in one Experimental animal and a single unusually low flow in one Control animal.

The clinical observation that stress-induced gastric mucosal ulceration begins in the proximal portion of the gastric body and progresses distally to, but usually does not involve, the antrum correlates with these findings of regional redistribution of blood flow in mild stress. While the gastric body mucosal flow decreased $62 \%$, the duodenal flow decreased $47 \%$, and pancreatic flow decreased $64 \%$ but there was no significant change in the antral mucosa. These are not unexpected findings since stress homeostatic mechanisms preserve MAP at the expense of visceral blood flow. Grund and coinvestigators [3] have shown that splanchnic nerve stimulation will cause a $32-45 \%$ reduction in gastric mucosal blood flow as determined by venous outflow studies. Assuming these results reflect sympathetic vasoconstriction, there is either less sympathetic control of the gastric antral flow than gastric body flow, or local mechanisms negate sympathetic effects in the gastric antrum. Whatever the mechanism, maintenance of adequate antral mucosal blood flow does appear to offer protection 
from the ischemic component of stressinduced ulceration.

\section{SUMMARY}

1. Following normotensive hemorrhage, significant reduction in blood flow affected the gastric body mucosa $(-62.3 \%)$, duodenum $(-46.9 \%)$, and pancreas $(-63.7 \%)$.

2. Following normotensive hemorrhage, no significant blood flow reduction occurred in the gastric antral mucosa.

3. Following normotensive hemorrhage, mucosal blood flow reduction was significantly greater in the cardia than in the preantral region.

4. Gastric antral blood flow is minimally sensitive to stress, suggesting a basis for the clinical observation of gastric body ulceration with antral sparing.

\section{REFERENCES}

1. Archibald, J., Moody, F., and Simons, M. Measurement of gastric blood flow with radioactive microspheres. J. Appl. Physiol. 38: 1051, 1975.

2. Broadie, T., Devedas, M., Rysavy, J., Leonard, A., and Delaney, J. Gastroduodenal blood flow in stress and hypoxia: An experimental approach. Surg. Forum 26: 397, 1975.

3. Grund, E. R., Reed, J. D., and Sanders, D. J. The effect of sympathetic nerve stimulation on acid secretion, regional blood flows and oxygen usage by stomachs of anesthetized cats. J. Physiol. (Lond.) 248: 639, 1975.

4. Hales, J. R. S. Effects of exposure to hot environments on the regional distribution of blood flow and on cardiorespiratory function in sheep. Pflüger's Arch. 344: 133, 1973.

5. Lucas, C. E., Sugawa, C., Friend, W., and Walt, A. Therapeutic implications of disturbed gastric physiology in patients with stress ulcerations. Amer. J. Surg. 123: 25, 1972.

6. Lucas, C. E., Sugawa, C., Riddle, J., Rector, F., Rosenberg, B., and Walt, A. "Stress" gastric bleeding. Arch. Surg. 102: 266, 1971.

7. Richardson, R., Norton, L., Sales, J., and Eiseman, B. Gastric blood flow in endotoxic-induced stress ulcer. Arch. Surg. 106: 191, 1973.

8. Ritchie, W. P. Acute gastric mucosal damage induced by bile salts, acid and ischemia. Gastroenterology 68: 699, 1975.

9. Shirazi, S. S., Mueller, T., and Marcus, M. Canine gastric blood flow measurements with gamma labelled microspheres during hemorrhage shock. Gastroenterology 70: A-79/937, 1976.

10. Utley, J., Carlson, E., Hoffman, J., Martinez, H., and Buckberg, G. Total and regional myocardial blood flow measurements with $25 \mu, 15 \mu, 9 \mu$ and filtered 1-10 $\mu$ diameter microspheres and antipyrine in dogs and sheep. Circ. Res. 34: 391, 1974.

11. Vatner, S. F., and Braunwald, E. Cardiovascular control mechanisms in the conscious state. $N$. Engl. J. Med. 293: 970, 1975. 